\title{
Patinar una carpeta: el grupo de trabajo del Auto 004 en la Dirección de Asuntos Indígenas
}

\section{To rollerblading a file: The 004 bill taskforce at the Indigenous Affairs Direction}

\author{
Valentina Pellegrino ${ }^{1}$
}

\begin{abstract}
Resumen
El artículo analiza el rol del grupo de antropólogos que trabajan en el cumplimiento de una orden judicial sobre protección a pueblos indígenas en riesgo de exterminio por cuenta del conflicto armado, al interior de la Dirección de Asuntos Indígenas del Ministerio del Interior en Colombia. A través de un trabajo de campo de diez meses, enfocado en sus rutinas laborales y obligaciones contractuales, la investigación encuentra que el quehacer del antropólogo no es el despliegue de su experticia profesional sobre los problemas de los indígenas en tanto insumo para tomadores de decisión, sino la gestión e intermediación en los procesos administrativos vinculados a la concertación entre los indígenas y las demás instituciones gubernamentales. Asimismo, el artículo destaca que, si bien su posición tiene un margen de maniobra limitado, es a la vez un rol complejo por la multiplicidad de posiciones que deben asumir en tanto mediadores y que los ponen en la encrucijada entre lo que aprendieron como antropólogos, lo que deben hacer como representantes del Estado y lo que hacen como ciudadanos. Finalmente, propone que esta labor, limitada y a la vez compleja, refleja un cambio en el quehacer de los antropólogos en la interacción entre el Estado y los indígenas.
\end{abstract}

Palabras claves: Dirección de Asuntos Indígenas; conflicto armado; quehacer del antropólogo

Tipología: Artículo de investigación.

Recibido: 29/09/2018

Evaluado: $06 / 11 / 2018$

Aceptado: $14 / 12 / 2018$

Disponible en línea: 24/12/2018

Como citar este artículo: Pellegrino, V. (2019). Patinar una carpeta: el grupo de trabajo del Auto 004 en la Dirección de Asuntos Indígenas. Jangwa Pana, 18 (1) 38-55. Doi: http://dx.doi.org/10.21676/16574923.2692

\footnotetext{
${ }^{1}$ Doctora en antropología. Universidad de los Andes. Correo electrónico: svalentinapellegrino@gmail.com.

Orcid: https://orcid.org/0000-0002-2559-2984
} 


\begin{abstract}
This article analyses the role of the anthropologist's group that works on the judiciary order of protecting the indigenous groups at extermination risk caused by the war, at the Direction of Indigenous Affairs of the Ministry of Interior. Through a ten month fieldwork focused on their job duties and work routines, it finds that their professional role is not about their expertise on the indigenous problematics used as input for decision-makers, but on managing and mediating between the indigenous people and the government institutions in the administrative processes related to the concertación between the indigenous people and the other government institutions. Additionally, the article highlights that even if they have a limited control and decision making in the process, their role is complex because it requires a multiplicity of positions to embrace as mediators, which puts them in the crossroads between what they learned as anthropologists, what they have to do as representatives of the State and what they do as citizens. Finally, it argues that this limited and complex work reflects a change in the anthropologists' duty related to the interaction between the State and the indigenous people.
\end{abstract}

Keywords: Directorate of Indigenous Affairs; armed conflict; work of the anthropologist

En 2009 la Corte Constitucional emitió el Auto 004 sobre 34 pueblos indígenas en riesgo de exterminio. En él planteó que los indígenas estaban en riesgo, tanto por el desplazamiento forzado que amenazaba su pervivencia física y cultural, como por la compleja articulación entre el conflicto armado, los intereses económicos en sus tierras y la pobreza en que se encontraban. Por ello, el Auto ordenó al Ministerio del Interior $^{2}$ crear e implementar 34 planes de salvaguarda para estos pueblos, los cuales debían ser consultados por ellos. Esta orden buscaba que el gobierno nacional resguardara efectivamente a una población que constitucionalmente es objeto de protección especial, pero además fue emitida en medio de un contexto adverso, pues el gobierno negaba la existencia del conflicto armado y subestimaba la dimensión y gravedad del desplazamiento forzado. Por eso la Corte acudía a la severidad de una orden judicial que implica obligatorio cumplimiento.

Al interior del Ministerio la Dirección de Asuntos Indígenas, ROM y Minorías se encargó de responder a la orden. En ese entonces era una entidad de tercer nivel, con escasos recursos y poco personal, pues se encargaba fundamentalmente de registrar y censar comunidades y autoridades indígenas, así como de ayudar a dirimir conflictos étnicos cuando fuera convocada; sin embargo, a raíz de la emisión del Auto 004, la dependencia se volvió central al recibir la mayor parte del presupuesto que se le designaba al ministerio, con lo que contrató a una serie de profesionales bajo la figura de orden de prestación de servicios para crear un grupo de trabajo, que en adelante llamaré "el grupo del Auto 04"3, y estableció una ruta metodológica con el fin de hacer frente a la

\footnotetext{
${ }^{2}$ La orden también iba para la ya extinta Acción Social, pero finalmente la asumió el Ministerio del Interior únicamente.

${ }^{3}$ Una forma en la que las personas no hacen parte del ministerio como funcionarios, sino que cumplen para este una serie de "servicios" establecidos en un contrato. Esto implica que no cuentan con vacaciones remuneradas y que deben pagar por sí mismos la totalidad de los dineros destinados a sus futuras pensiones y a su seguridad social. Generalmente los contratos son a tres o cuatro meses, pero se renuevan constantemente, lo que deja a las personas en el limbo económico durante las semanas que esta renovación pueda tardar. Como supuestas ventajas está que el contratista puede "disponer libremente de su tiempo" puesto que no se le paga por horas sino por el cumplimiento de las obligaciones pactadas; sin embargo, en Colombia es frecuente que este mecanismo de contratación sirva para tener trabajadores desempeñando funciones públicas y cumpliendo con horarios laborales de forma similar a la de los funcionarios, pero sin tener acceso a las prestaciones de aquellos, algo que al menos en la Dirección de Asuntos Indígenas no era tan frecuente.
} 
titánica tarea de crear los planes de salvaguarda que ordenaba el Auto.

Mi investigación doctoral consistió precisamente en comprender cómo se dio cumplimiento del Auto, así que hice trabajo de campo durante casi un año acompañando y entrevistando al grupo del Auto 04 durante su cotidianidad laboral en las instalaciones del ministerio y en algunos de sus viajes a los territorios indígenas. Ahora bien, una particularidad de este grupo es que la mitad más uno de sus once integrantes eran antropólogos y el resto eran profesionales en otras ciencias sociales. Considero que un análisis sobre la labor de estos colegas en el ministerio, que estaban involucrados en un tema tan relevante como la protección gubernamental a pueblos indígenas en medio del conflicto armado, permite aproximarnos a una posición que ocupan actualmente los antropólogos en la función pública en Colombia. Por eso, en este artículo exploraré específicamente el trabajo que hacían. Así, tras describir su condición al interior del ministerio y su dinámica laboral dentro de la ruta metodológica establecida para cumplir con el Auto, plantearé las encrucijadas que enfrentan en su trabajo como producto de la compleja y a la vez limitada posición que ocupan. En la primera sección introduzco al grupo del Auto 04 en relación con su posición dentro del ministerio; en la segunda, describo en qué consiste su trabajo; y en la sección final, planteo los dilemas a los que se enfrentan, así como la relación entre estos y las dinámicas históricas de la antropología. Con base en ello, sostengo que el oficio de los antropólogos al interior del grupo del Auto 04 consiste fundamentalmente en labores administrativas de gestión, supervisión y coordinación del proceso de elaboración de los planes de salvaguarda. En esa medida, buena parte de su labor consiste en revisar y tramitar en el entramado administrativo de las instituciones gubernamentales los documentos producidos como respuesta al Auto y que hacen parte del proceso de elaboración de los planes de salvaguarda; de ahí que su trabajo se pueda sintetizar en "patinar carpetas", término que retomaba uno de los antropólogos del grupo para describirlo y que hace referencia, en el argot de los tinterillos, a mover con rapidez los documentos necesarios para un caso en distintas oficinas. Esta labor refleja una tensión no solo con el oficio de antropólogo desde la academia, sino también con los supuestos de la antropología aplicada. Así, entiendo este patinar carpetas como un reflejo del cambio en el tipo de mediación que ejercen los antropólogos en la relación entre los indígenas y el Estado.

\section{Llegar al recoveco}

Una mañana me encontraba en la oficina del grupo del Auto cuando la dependencia del ministerio que tramita los pagos llamó a R, uno de los antropólogos del grupo, para informarle que le faltaba un papel en los documentos que radicó con su cuenta de cobro, por lo que podía esperar un retraso en la consignación de ese mes. Aunque siempre tenía la sonrisa a flor de piel y la paciencia casi budista de quien ha sobrevivido a cientos de reuniones gubernamentales, $\mathrm{R}$ no pudo evitar molestarse, especialmente porque hacía tiempo que había llevado el papel. Así que, tras la llamada, mientras imprimía nuevamente el desaparecido documento y se alistaba para llevarlo a la oficina del director para que lo firmara otra vez, me dijo con rabia y algo de desaliento: "yo estudié antropología para no hacer estas cosas".

La frase retumbaba en mi cabeza cuando fuimos al despacho del director de Asuntos Indígenas, en el sexto piso del edificio, cuya firma dependía dar trámite a casi cualquier documento de la Dirección, así que, en su escritorio, delante de un retrato al óleo del famoso taita Querubín del Putumayo, yacía la pila de documentos de 30 cms de alto con tiritas de colores que le indican dónde debe ir su rúbrica en cada papel. $\mathrm{R}$ sumó entonces uno más a la enorme pila y, una vez garabateada la firma, lo llevó de vuelta a su escritorio, y tras salir de la oficina del director, atravesamos las oficinas de las dependencias misionales de Asuntos Indígenas, cruzamos la habitación en donde están apretujadas las cientos 
de carpetas con los últimos años de trabajo administrativo, bajamos tres pisos por los corredores de oficinas abandonadas y cajas con documentos que acumulaban polvo, recorrimos luego el pasillo del tercer piso y llegamos, por fin, a la oficina del Auto 004.

El intrincado trayecto para llegar del Auto 004 a la oficina del director es poco transitado porque se hace desde las entrañas del edificio y llega internamente desde las dependencias misionales de Asuntos Indígenas que están en el sexto piso. El efecto espacial del camino es que, si bien la oficina del Auto no hace parte del resto de oficinas de Asuntos Indígenas del sexto piso, hay una conexión tangible que es el recoveco: confuso, largo, dispendioso, obstaculizado con cientos de documentos y, como todo laberinto, hay que aprenderlo a recorrer. Imagino que la retahíla de eventos violentos que motivaron la declaración del Auto 004, es decir, todas aquellas denuncias que la corte recibió sobre hostigamientos y asesinatos a indígenas, deben estar al menos parcialmente presentes en esas cajas con carpetas del archivo muerto de la dirección, o en el intersticio del trabajo sobre conflictos y derechos humanos que se lleva a cabo en las oficinas del sexto piso que, mediante este pasadizo, se conectan con los recintos del grupo del Auto 004.

Posiblemente, el grupo no estaba en el mismo espacio del sexto piso del resto de Asuntos Indígenas porque su trabajo obedecía a una orden judicial que tenía un tiempo estipulado de cumplimiento de seis meses y no era una competencia misional de la dirección, que debe cumplirse permanentemente. De ahí que el espacio que se les acondicionó se pensó inicialmente de forma tan temporal como la orden; incluso estuvo inicialmente por fuera de las instalaciones del ministerio, en una oficina arrendada, hasta que se reparó en la conveniencia de que el grupo trabajara más cerca a las oficinas de Asuntos Indígenas, pues la situación coyuntural del cumplimiento del auto se había vuelto cada vez más permanente y el plazo inicial de seis meses que dio la corte se había demorado de tal modo que, para el momento en que hice mi trabajo de campo, habían transcurrido cuatro años y aun hoy, nueve años después, continúa en proceso.

Pienso que el laberinto que conecta a las oficinas del Auto 004 con las del resto de Asuntos Indígenas es una metáfora espacial de la relación entre el grupo del auto y la dirección, pues está simultáneamente fuera de la dirección, pero conectado a ella, lo que refleja de esta forma la intrincada posición que el grupo ocupaba en el Ministerio del Interior, como si estuvieran fuera de lugar dentro de la institución. Esto se evidenciaba, por ejemplo, en que mientras los funcionarios de la dirección cuentan con un usuario para acceder al software institucional donde se radican y procesan los documentos, el grupo del Auto debía compartir el usuario y contraseña que les prestaba un funcionario de planta, porque para el sistema no hacían parte de la institución, así trabajaran allí. La diferencia entre ellos y el resto de gente que trabajaba en el ministerio era además visible en el contraste entre las mochilas, el pelo largo y los jeans que usaban los integrantes del grupo y las corbatas del resto de oficinistas de la institución; por lo que en la entidad los apodaban, no muy ingeniosamente, los mechudos.

Ellos, que no llegaban a los treinta años y en su mayoría se encontraban por primera vez trabajando en el sector público, estaban formados en ciencias sociales y más de la mitad en antropología, una disciplina que nada les enseñó sobre cómo elaborar política pública o sobre administración pública. De hecho, solo dos de los integrantes del grupo, los únicos politólogos, habían trabajado antes en el sector público y tenían experiencia en aquel enrevesado mundo. El resto venía de trabajar con organizaciones indígenas o de culminar tesis (de pregrado o maestría) con pueblos cobijados en el auto; aunque no faltaba quien había mediado en consultas previas entre empresas privadas y comunidades indígenas, así como un par que no habían trabajado antes con indígenas ni en el sector público, pero que se hicieron un lugar en 
el grupo del Auto 004 gracias a su título profesional como antropólogos o, en otros casos, a la curiosa presunción del director de Asuntos Indígenas de que por tomar yagé eran perfectos para trabajar allí, porque consideraba que eso demostraba cierta sensibilidad frente a estos pueblos y sus prácticas ${ }^{4}$. A pesar de no tener experiencia previa trabajando al interior de una entidad gubernamental, estos mechudos, distintos y distantes de los funcionarios de planta, franquearon el recoveco de la institución, atravesando los confusos, largos y dispendiosos procedimientos inundados de papeleo que constituían su trabajo.

\section{El oficio de patinar carpetas}

El comentario de $\mathrm{R}$ sobre estudiar antropología para no hacer estas cosas implica que nos detengamos, por un lado, en qué cosas estaba haciendo como parte de su trabajo en el grupo del Auto 04 y, por el otro, en qué cosas son las que, se supone, deberían hacer los antropólogos. Así, en cuanto a qué hacían, me detendré inicialmente a la ruta metodológica que desde allí se estableció para dar cumplimiento al Auto 004. El primer paso de la ruta consistía en socializar el auto entre los pueblos indígenas concernientes, es decir, que los indígenas supieran en qué consistía la medida. Luego, se haría un diagnóstico en el que se plantearan cuáles eran los principales problemas en relación con el conflicto armado y el desplazamiento forzado; a continuación, se entraría en una fase de concertación entre los pueblos indígenas y las instituciones gubernamentales para que, como resultado de la misma, se llegara a la fase final de formulación de los planes de salvaguarda. Acá vale la pena resaltar que el diagnóstico no lo elaboraba el ministerio sino las organizaciones indígenas, aunque financiadas y supervisadas por la entidad.

\footnotetext{
${ }^{4}$ No me detendré acá en lo exotizante de la presunción, pero el trabajo de Uribe (2002), Sarrazin (2012 y 2015) y Caicedo (2015) brinda luces sobre los significados
}

En consecuencia, la labor de $\mathrm{R}$ y los demás integrantes del grupo, enmarcado en esta ruta metodológica, consistía en socializarles el auto a los distintos pueblos indígenas; adelantar todas las negociaciones y trámites administrativos necesarios para crear convenios en los que el ministerio daría dinero y las organizaciones a su vez se comprometían a hacer el diagnóstico; supervisar la elaboración de estos diagnósticos y hacer las gestiones internas en el ministerio para adelantar los pagos a las organizaciones; una vez los diagnósticos estuvieran listos, convocar a las instituciones gubernamentales para establecer las negociaciones entre estas y las organizaciones indígenas sobre las medidas a tomar; servir como mediadores en estas negociaciones y asistir en la formulación de lo que quedara como resultado de las mismas. Además, como cualquiera que trabaje en la función pública, de vez en cuando debían responder derechos de petición y solicitudes de información o elaborar los reportes que pidieran los entes de control, la corte, las organizaciones indígenas o cualquier ciudadano interesado en el Auto 004.

Por ende, a primera vista, el trabajo de la gente del grupo era sencillo, puesto que no recaía en ellos elaborar los planes de salvaguarda que ordena el Auto 004, sino apoyar a los indígenas que las hacen, como quedaba establecido en los convenios que adelantaban entre el ministerio y las distintas organizaciones indígenas. Por apoyo, el ministerio entendía facilitar tanto los escenarios gubernamentales como los recursos económicos necesarios para que entre los indígenas y las instituciones formularan los planes de salvaguarda. Esto se traduce en la convocatoria y coordinación de decenas de reuniones; así como en la elaboración, revisión, radicación y seguimiento a cientos de documentos con formatos y lenguajes institucionales para convocar y registrar dichas reuniones, además de autorizar y ejecutar presupuestos. Así que buena parte de su trabajo

atribuidos por las clases medias y profesionales a las prácticas alrededor del yagé. 
era redactar, completar y tramitar actas, relatorías, informes, convocatorias, formatos de comisiones de viaje y cuentas de cobro.

Por último, cabe aclarar que, dado que el Auto cobijaba a 34 pueblos, cada integrante del grupo trabajaba en el proceso de dos o tres pueblos. Además, cada proceso estaba en una etapa diferente porque no se iniciaron todos al tiempo y además por la relación entre cada pueblo y el Ministerio del Interior, marcada por la historia particular de interacciones previas entre el Estado y cada pueblo. Además, un pueblo podía contar con múltiples diagnósticos debido a que estaba conformado por comunidades bajo circunstancias diferentes o con divisiones internas, así, por ejemplo, los emberá no tenían uno sino diecisiete procesos de diagnóstico en marcha, para perpetuo agotamiento de $\mathrm{H}$, encargado de aquellos. Todo esto para decir que, aunque el papeleo y la gestión de la ruta metodológica fueran los mismos, un mismo integrante del grupo podía llevar un proceso más adelantado, o menos problemático con un pueblo que con otro.

En la socialización, un miembro del grupo del Auto 004 les explicaba a los indígenas los puntos principales del documento, lo cual también implicaba introducirlos a la forma en la que el ministerio consideraba que debían usarlo. Aunque algunos integrantes usaban la presentación PowerPoint extensa y sobrecargada de texto que alguien hizo años atrás, otros preferían un enfoque más informal, pero en ambos casos destacaban ciertos principios sobre qué debía y no debía hacerse con el auto. Esto lo vi cuando acompañé a C, coordinador del grupo, a una reunión de socialización del auto con los wayuus en Uribia, departamento de la Guajira y empezó a contarles a los asistentes, unas doscientas personas entre hombres, mujeres y niños, en qué consistía el Auto 004, cómo había surgido de una sentencia de la Corte Constitucional y, dado que los alijunas 5 hacen

${ }^{5}$ personas que no son wayuu. todo por escrito, explicarles que el auto era un documento y este ordenaba hacer un plan de salvaguarda. Enfatizó que los planes de salvaguarda no son una entrega de dinero y que, por el contrario, son el resultado de la concertación entre el pueblo wayuu y las instituciones del gobierno, que se daría luego de que los wayuus culminaran un estudio sobre los problemas que los aquejan y las posibles soluciones a los mismos. Lo interesante es que acá emergía la interpretación que Asuntos Indígenas promovió como espina dorsal de la ruta metodológica y que no hace parte de la orden explícita del Auto 004: los indígenas no solamente debían diagnosticar sus problemas sino también proponer las soluciones, porque ellas serán la base para acordar con las instituciones qué se hará como plan de salvaguarda.

Así, a los indígenas les fue trasladada la responsabilidad de plantear cuáles serían las medidas y acciones que debían tomarse para protegerlos ${ }^{6}$. Ahora bien, si quedaba en manos de los indígenas definir cuáles son los problemas que los aquejan y proponer la forma de resolverlos, entonces el trabajo de los científicos sociales que conformaban el grupo del Auto 004 en Asuntos Indígenas consistía en facilitar administrativamente que esto fuera posible. Para ello se firmaban los convenios de asociación entre las organizaciones indígenas y el ministerio, en el que las primeras se comprometían a elaborar los diagnósticos con propuestas y la entidad se comprometía a financiar la elaboración de los diagnósticos.

Pienso que el trabajo de la gente del grupo del Auto 004, principalmente el hecho de que su intervención fuera sobre aspectos administrativos, refleja el cambio del rol de los científicos sociales en el marco del neoliberalismo en tanto régimen de gobierno. En ese sentido, vale la pena matizar los planteamientos de Rose (1997) sobre el cambio

${ }^{6}$ En otro texto (Pellegrino 2017) analizo las implicaciones del traslado de esta responsabilidad y su vinculación con lógicas de multiculturalismo neoliberal. 
en la manera de gobernar en el tránsito del liberalismo al neoliberalismo y la transformación que encuentra en la relación entre los expertos y la política en los dos regímenes. Así, si en el liberalismo se vinculaba al gobierno con conocimientos desarrollados por las ciencias sociales, a cuyos expertos se les confería autoridad, en el neoliberalismo en cambio esta autoridad se transfirió a los regímenes calculadores de contabilidad y gestión financiera.

Sin embargo, el tránsito hacia regímenes neoliberales también ha implicado la adopción de un multiculturalismo de Estado en muchos países. La adopción de medidas para el reconocimiento de los pueblos indígenas y de un enfoque diferencial en la política pública en Colombia ha implicado crear grupos o divisiones en varias instituciones estatales que se encarguen de los temas étnicos ${ }^{7}$. Por eso al interior de la institucionalidad del Estado colombiano los científicos sociales (particularmente los antropólogos) siguen encontrando trabajo, pues hacen parte de las áreas que manejan el tema étnico en cada institución; pero, además, su trabajo ha aumentado no solamente en las agencias gubernamentales, sino también en las organizaciones indígenas que empezaron a depender más de asesores externos para interactuar con el Estado (Padilla 1996). Es en este contexto en que gente como $\mathrm{T}$ o $\mathrm{N}$ transitan entre trabajos con organizaciones indígenas $\mathrm{y}$ trabajos en el Ministerio del Interior.

En el caso de diseñar e implementar políticas públicas como las que propone el Auto 004, lo que vemos es que si bien los científicos sociales no son reemplazados en el gobierno por expertos financieros como esperaba Rose, su autoridad ha cambiado en la medida en que su labor se vincula más a navegar los océanos administrativos para gestionar los convenios y a supervisar el trabajo de los indígenas, en lugar de ser quienes

\footnotetext{
${ }^{7}$ Por ejemplo, en el DANE se creó la Unidad de Grupos Étnicos, en el Ministerio de Protección Social está el Grupo de Asuntos Étnicos y de Género y el ICBF cuenta
}

conceptualicen los problemas y las soluciones para salvaguardarlos.

Ahora bien, esto confluye con la creciente participación de los indígenas en la elaboración de las políticas basadas en el multiculturalismo, la cual es objeto de un debate entre quienes entienden esta participación como un logro de los movimientos indígenas (Pineda 1997, Jimeno 2007 y 2011) y los que la conciben dentro del marco de un proyecto cultural neoliberal (Grey Postero 2007, Hale 2002 y 2004, Briones 2007). En cualquier caso, para lo que nos concierne, esta mayor autonomía y participación de los indígenas en la formulación de las políticas que los atañen ha implicado una transformación en el rol del antropólogo como mediador y traductor de las condiciones y demandas indígenas, pues ellos las plantean por sí mismos; en ese contexto, se comprende que no sea responsabilidad de los integrantes del grupo plantear los planes de salvaguarda.

Sin embargo, los indígenas debían adecuarse a los formatos, lenguajes y tiempos institucionales en su elaboración de los diagnósticos. Por ello, su trabajo era supervisado por los integrantes del grupo del Auto 004, quienes debían revisar que se cumpliera con ciertos formatos y pautas en la documentación. Así, por ejemplo, para L había cosas puntuales que debían incluir los indígenas en los informes técnicos sobre la elaboración de un diagnóstico. Al supervisar un informe técnico, L notó que no estaba señalada la socialización del Auto 004 como uno de los puntos de la reunión. Sin embargo, a él le preocupaba que no estuviera la frase "se hizo la socialización del Auto 004", mas no que no hubieran socializado el auto, porque sobre esto último no tenía dudas. Para L era importante que los indígenas fueran cuidadosos en esos detalles porque consideraba que de esta manera ayudaba en la consolidación de las organizaciones, que estarían mejor equipadas para luego presentar proyectos con instituciones públicas o privadas.

con el Programa para Comunidades Étnicas y Rurales, entre otras instituciones. 
Este tipo de correcciones eran comunes en la supervisión que realizaba el grupo.

La supervisión implica la promoción de una forma en que los indígenas deben relacionarse con la institucionalidad, mediante el empleo de los lenguajes, formatos y lógicas que se usan en el entramado institucional para hacer política pública y que los harían más adecuados para interactuar a futuro con funcionarios (Jaramillo A. 2016). Lo que acá me interesa es señalar que parte del trabajo del grupo del Auto 004 en cuanto a la supervisión de los diagnósticos radicaba en fomentar esta dimensión administrativa del indio permitido de Hale (2004), en el sentido en que consiste en asesorar y supervisar cómo presentar más adecuadamente la información sobre las propuestas; pero a la vez no entraban específicamente a evaluar las propuestas que presentaban los indígenas ni planteaban qué tipo de medidas eran más deseables o más acordes con los programas gubernamentales.

Ahora bien, buena parte de sus labores de gestión, supervisión y coordinación quedaban documentadas y almacenadas en las carpetas que recogen la información de un proceso de salvaguarda. Así, las carpetas contenían los convenios de asociación que ellos redactaban (junto con la gente de las oficinas jurídicas del ministerio), los informes técnicos que las organizaciones indígenas presentaban y que ellos tenían que revisar, las actas de reuniones, de comités y de talleres, con sus correspondientes listados de asistencia con las que las organizaciones indígenas certificaban el trabajo hecho y que ellos revisaban y archivaban, las cuentas de cobro de las organizaciones que tramitaban al interior del ministerio, las convocatorias que hicieran para las reuniones de concertación y sus actas, más un largo etcétera de documentos que atestiguaban imprevistos. Por ello, la carpeta es la metonimia de las

${ }^{8}$ En diciembre de 2013 conté 5 cambios de un mismo formato para ese mes, de ahí que los trámites se repitan varias veces, pues cada vez hay que ajustarlo al nuevo formato. interacciones oficiales que tiene el ministerio con determinada organización, pues todas aquellas tareas de supervisión y gestión quedan consignadas allí.

En consecuencia, patinar una carpeta tenía que ver con agilizar el proceso que estaba allí contenido, esto implicaba lograr pagos a las organizaciones indígenas más expeditos al interior del ministerio o incluso convencer a los funcionarios de distintas instituciones para que fueran a las reuniones que convocaban los indígenas. Así, por ejemplo, el trabajo del grupo implicaba buscar y diligenciar los formatos para los pagos $^{8}$, subir toda la documentación concerniente a los pagos en el software del ministerio (SIGOB) y asegurarse de que los recursos fueran enviados a las cuentas bancarias de las organizaciones. Esto incluía lograr que los pagos a los indígenas se hiciera a tiempo, lo cual no se debe únicamente a la rapidez de conseguir y organizar los documentos necesarios, sino también a la buena relación que la persona del grupo tenga con los funcionarios en las oficinas financiera y contractual del ministerio, para ver si pueden acelerar un poco el pago. Como me decía D, el antiguo coordinador del Auto 004, en esto la simpatía es fundamental:

Uno tiene que aprender a ver la frustración, pero también a ver las cosas lindas, creer en lo que está haciendo y jugársela y entregársela toda, dársela toda y eso significa llevarle el dulcecito a la señora Fulana y a los de Jurídica, que cargue una bolsita y vaya y lleve y saque, sea querido y pele las muelas, pero es que aquí toca así todo: "ipero es que acá debe haber un procedimiento!". Sí hermano, lo que quiera, [pero] para que esto funcione hágame el favor de llevarle dulces para que esto salga o si no, podemos esperar a que esto cambie [y] estructuralmente no vamos a hacer nada. ${ }^{9}$

\footnotetext{
${ }^{9}$ Entrevista con D, antiguo coordinador del grupo del Auto 004 en el Ministerio del Interior, conducida por Valentina Pellegrino, 30 de octubre de 2013.
} 
Por supuesto, cualquiera que haya tenido que interactuar con funcionarios públicos para tramitar u obtener algo, sabrá que hay mayores posibilidades de obtener el resultado en el tiempo deseado si se establece una relación cordial con el funcionario encargado. La gente del grupo del Auto 004, en sus interacciones con los funcionarios del ministerio, sabía que no era la excepción. Por otra parte, tramitar los pagos no necesariamente implicaba que la documentación estuviera perfecta sino que, en caso de contener errores menores, hay que ser carismático para impedir que esto detenga un proceso de pago y en esto $\mathrm{K}$ tiene un don por su simpatía, útil cuando en una de las cuentas de cobro de los indígenas había "O" (la vocal) en lugar de " 0 " (cero). Aunque es un simple error de digitación y no cambia el sentido de lo que se pretendía enunciar, el funcionario de la división financiera del ministerio se encargó de hacerle saber profusamente que le estaba haciendo un gran favor al recibirle el papel con ese error. Sin este gesto del funcionario de financiera y sin la simpatía de $\mathrm{K}$, el trámite de pago habría demorado una semana más, por ende la carpeta patinó exitosamente a pesar del error. De ahí que no fuera superfluo el consejo de su antiguo jefe sobre "pelar los dientes" y cargar con dulces para los funcionarios.

En cuanto a la concertación, su tarea era convocar a las distintas entidades públicas para que asistieran y participaran en la concertación de las propuestas que tenían los indígenas, y que podían consistir en medidas puntuales, creación de programas institucionales o la atención a demandas históricas. Además de convocar, en las concertaciones los integrantes del grupo actuaban en representación del ministerio como intermediarios entre los indígenas y los funcionarios de las diversas entidades; y se encargaban asimismo de dejar constancia en las actas y relatorías sobre los compromisos que adquirían las instituciones. Ahora bien, la obligación del ministerio es hacer las convocatorias a estas reuniones, es decir, enviar una invitación oficial por escrito (y por ende rastreable con el código de radicación en cada entidad); pero queda por fuera de su responsabilidad que atiendan o no la invitación y casos se habían visto de entidades que simplemente no llegaban a las concertaciones.

Por eso me pareció tan admirable el esfuerzo de B cuando citó a una reunión de los funcionarios de distintas instituciones para asegurarse de que realmente viajarían a Nariño a encontrarse con los awá, pues precisamente por esos días, líderes de estos pueblos bloquearon la vía mientras manifestaban por la situación de confinamiento en la que viven, sumada al incremento de la minería ilegal en sus territorios. Esa tarde, el monótono ritmo de una reunión interinstitucional cambió por los melódicos sonidos de una marimba, pues B puso un disco compacto con los ritmos que, según les contó a los asistentes, suelen escucharse al inicio de las reuniones con los awá.

No es un secreto en el mundo de las oficinas de asuntos indígenas de las diversas instituciones nacionales que los awá son conocidos como un pueblo belicoso, pues con ellos, según afirmaban algunos de los funcionarios que asistieron a dicha reunión, se daban acuerdos de carretera, es decir bajo la presión de las vías de hecho como el bloqueo de carreteras. B, enfundado en su chaqueta de cuero negra y sus lentes oscuros que lo hacían ver como un heredero de Jim Morrison criollo, intentó presentar a los paisanos awá con otra luz, más cálida. Ante veinte funcionarios que se habían declarado preocupados por viajar, habló de cómo la gente en los resguardos está en la inmunda, pues no tienen luz ni agua, cómo a pesar de que hay un acompañamiento humanitario están constantemente bajo el fuego cruzado, cómo el confinamiento los afecta sobremanera por su patrón de asentamiento, cómo haciendo trabajo etnográfico en el territorio se percató de que hay un enorme abandono del Estado aunque también hay escuelas muy bacanas, cómo la guardia indígena ha protegido a los policías y están cansados de que los asocien con la guerrilla, cómo el bloqueo que estaban haciendo era 
pacífico y cómo vivir en la maraña del conflicto es complicado.

Esta maraña la atestiguaría $\mathrm{B}$ unos meses más tarde, cuando en una reunión en territorio awá pusieron literalmente sobre la mesa -cubiertos por un plástico- los dos cadáveres de los miembros de la comunidad que habían sido recientemente asesinados. Situaciones como esa influyeron en la vehemencia con que intentaba mover el proceso de salvaguarda en Bogotá, en la emotividad con la que hablaba y su interés por explicarles a sus pares de otras instituciones que la complejidad del escenario awá no podía reducirse a que buscaran hacer acuerdos de carretera, como una forma para intentar convencerlos de la importancia de que las instituciones gubernamentales actuaran para restituir sus derechos y protegerlos, como era la intención del Auto 004, puesto que ni B ni la Dirección de Asuntos Indígenas puede obligar a otras instituciones a actuar, así hubiese una orden judicial de por medio.

En síntesis, su rol estaba prioritariamente vinculado a la gestión administrativa, al procurar los escenarios y documentos necesarios para que los indígenas plantearan directamente sus propuestas y para que pudieran concertarlas con las instituciones, lo cual implicaba cuestiones tan puntuales como gestionar los recursos, pero también esfuerzos por persuadir a los funcionarios de las instituciones sobre la urgencia de la situación de los indígenas. En este rol administrativo no hay mayor participación del grupo en la conceptualización de los problemas ni en la estipulación de medidas gubernamentales para subsanarlos, lo cual tiene que ver con la pérdida de centralidad de las ciencias sociales en los saberes considerados como necesarios para gobernar $y$, específicamente, en cuanto al gobierno de los pueblos indígenas, al grado y tipo de participación que estos han alcanzado en las discusiones sobre políticas públicas para ellos, en los que la intermediación de los antropólogos, en cuanto expertos que hablan en nombre de los indígenas al interior del Estado, ha decrecido.
Ahora bien, las labores del grupo, y en particular cómo las asumían los antropólogos del mismo, entrañan en su mundana simpleza toda la complejidad de la posición que ocupaban como representantes del Estado colombiano frente a las organizaciones indígenas y también reflejan las tensiones del quehacer antropológico, como pretendo mostrar en la siguiente sección.

\section{La encrucijada de los antropólogos: ¿infiltrados en el Estado?}

La cuestión que queda pendiente es ver qué se supone que debería hacer la antropología, como para que personas como $\mathrm{R}$ plantearan que estudiaron esta disciplina para no hacer estas cosas que hacía en el ministerio y por extensión, en el Estado; especialmente si consideramos que la disciplina ha estado vinculada desde sus inicios a procesos de construcción del Estado, por sus roles diversos en la administración de poblaciones indígenas, que van desde la intervención hasta la intermediación (Pels 1999, L'Estoile, Neiuburg y Sigaud 2005). Sin embargo, como se desprende de la sección anterior, el trabajo de los antropólogos en el ministerio para cumplir con el auto no consistía precisamente en conceptualizar los problemas de los indígenas, como ocurre cuando se contrata antropólogos en tanto expertos que brindan a los tomadores de decisión un conocimiento especializado (Pacheco de Oliveira 2005) y ni siquiera en hacer evaluaciones rápidas (Pérez 2007); sino en patinar carpetas. De ahí parte de la explicación sobre cómo $\mathrm{R}$ estudió antropología para no hacer estas cosas.

Ahora bien, en el contexto colombiano, aunque una forma de ejercer la antropología es seguir la vida académica en la que las investigaciones, publicaciones, debates y carrera docente son la norma y la relación con el Estado es en cierta 
medida indirecta ${ }^{10}$, es mucho más común el camino de la antropología aplicada (Pineda 2004 y 2005, Jimeno 2008). Con este camino se pretende usar los conocimientos y métodos de la disciplina para identificar, evaluar y resolver problemas sociales, lo cual puede darse desde organizaciones de base e instituciones no gubernamentales o desde instituciones gubernamentales.

De hecho, un escenario que históricamente se constituyó para hacer antropología aplicada ha sido Asuntos Indígenas, pues buscó materializar un espacio gubernamental para generar instrumentos con miras a la transformación de las condiciones precarias de los indígenas; todo ello bajo la inspiración del indigenismo oficial ${ }^{11}$ (Correa y Acero 2013). En ese sentido, vale la pena explorar las encrucijadas de colegas como $\mathrm{R}$ a la luz de las transformaciones del quehacer antropológico en relación con aquellas oficinas que conectan al recoveco. Casi cincuenta años antes de la creación del grupo del Auto 004, Gregorio Hernández de Alba, el primer antropólogo profesional colombiano, fue también el primer director de Asuntos Indígenas del Ministerio (García 2010). Aquella primera generación de antropólogos del país a la que pertenecía era crítica de las condiciones de marginalidad y pobreza de los indígenas, por lo que buscó ayudar a incorporar social y económicamente a los indígenas dentro de la sociedad mayoritaria, pues veían esto como algo inevitable (Langebaek 2009, Correa 2006).

Por ello en 1960, cuando llegó a dirigir Asuntos Indígenas en el entonces Ministerio de Gobierno, planteó iniciativas que buscaran intervenir en asuntos de higiene, salud, economía, alimentación y educación; todo ello se entendía como una integración social que respetara la propiedad colectiva de sus tierras y

10 Como empleador si se trabaja en una universidad pública y como patrocinador de investigaciones si estas se hacen desde instituciones científicas con fondos públicos.

${ }^{11}$ Acá me refiero al indigenismo mexicano que se originó en el Congreso Indigenista de Pátzcuaro en 1940 y que buscó impulsar un tipo de intervención estatal que, más que se presentaba como respetuosa de los valores culturales indígenas. Para ello, en el decreto con el que se creó se establecía como propósito estudiar a las poblaciones indígenas para ver cuáles podrían ser los cambios aconsejables (Jimeno 2008), es decir, que se asumía a la antropología como un saber que además tenía la responsabilidad de ayudar a transformaciones sociales, aunque desde aquella perspectiva, estas eran un asunto del Estado (Correa 2006). De ahí que el rol de antropólogos como Hernández de Alba en Asuntos Indígenas encarna toda una postura de la disciplina en los tempranos años sesenta, que estudiaron para hacer esas cosas que se hacían en aquellas oficinas.

En los años setenta la política de la División de Asuntos Indígenas se fue transformando en línea con los planteamientos regionales sobre desarrollo y con una perspectiva asistencialista (Acero y Correa 2013). Además, la oficina no parecía tener relevancia al interior del Estado colombiano; de hecho, tanto en los documentos de fundación del CRIC como en los de los años iniciales de la ONIC, se menciona su rol como algo minúsculo y se referencia los esporádicos que eran en aquel entonces sus programas, a tal grado que uno de los puntos fundacionales del CRIC era que se eliminara dicha oficina (Ministerio de Cultura 2010). Asimismo, su relación con los pueblos se volvió indirecta, pues el deber de Asuntos Indígenas era ahora vigilar a las corporaciones y fundaciones constituidas para desarrollar actividades relacionadas con las comunidades indígenas (Decreto 1741 de 1973).

De forma paralela a estas transformaciones en la dependencia administrativa, la nueva generación de antropólogos planteaba una antropología militante, en el sentido de estar involucrada abiertamente con los indígenas y su movimiento

allá de proyectar políticas para mejorar las condiciones de vida de los indígenas, planteaba mediante ellas su integración a la nación. No me refiero al concepto de Alcida Rita Ramos (2011) de indigenismo en tanto orientalismo americano. 
social, que en aquel entonces empezaba a agruparse en torno a organizaciones. Estos antropólogos asumían su profesión como un compromiso, entendido como un vínculo político y moral con estas comunidades; algo que no estaba únicamente en quienes trabajaban directamente con las organizaciones indígenas o en la academia, sino también en antropólogos que trabajaban desde las instituciones gubernamentales (Jimeno 2008).

Ahora bien, a finales de los ochenta empezó un viraje en la forma en que el Estado concebía la relación con los indígenas, la cual se cristalizó con la declaración en la Constitución Política de 1991 como un país multicultural y pluriétnico. De esta forma, se pasó de un paradigma de la integración que buscaba una transformación cultural dirigida a un paradigma del reconocimiento y la exaltación de la diferencia cultural. Esto implicó adecuaciones institucionales que generaron la apertura de decenas de oficinas de Asuntos Indígenas en otras tantas entidades gubernamentales, además de una serie de ajustes al interior de las organizaciones indígenas, para hacerle frente a nuevas formas de interlocución con el Estado.

Antropólogos como los integrantes del grupo del Auto 004 hacen parte de esta nueva relación entre el Estado y los indígenas, cuya vocería está en organizaciones indígenas ya consolidadas. Además, la interacción está atravesada por la realidad del recrudecimiento de la violencia que, como señala Lemaitre (2009), hace parte de lo que el multiculturalismo se ha negado a reconocer, de la misma forma en que desconoce las marginalizaciones políticas y económicas (Chaves 2011). En este contexto de violencia directa y sistémica, su posición en tanto representantes del Estado no era únicamente limitada (como vimos en la sección anterior) sino compleja, pues requería una intermediación permanente entre los indígenas y los funcionarios tanto del ministerio como de las demás instituciones gubernamentales que debían participar en la elaboración de los planes de salvaguarda ordenados en el Auto 004 y estas intermediaciones implicaban una constante reflexión sobre su posición, sus compromisos y su formación.

Así que no era una tarea sencilla, no porque implicara un constante ir y venir entre los territorios indígenas y las diferentes oficinas donde se deben tramitar los asuntos administrativos del convenio, sino porque implicaba oscilar entre múltiples posiciones, pues debían mediar por una parte con los indígenas, quienes los inquirían por las dilaciones e insuficiencias en un proceso sobre el cual no tenían mucha capacidad de decisión; por otra parte, debían mediar con los funcionarios dentro del Ministerio, por quienes eran percibidos como voceros de los indígenas por hacer parte de la Dirección de Asuntos Indígenas $\mathrm{y}$ por presionar para agilizar o flexibilizar trámites en nombre de los indígenas; y también mediaban con los funcionarios públicos de las demás instituciones, para quienes ellos eran representantes del ministerio y los atribulaban con decenas de reuniones. Esa mediación los hacía estar inmersos en una enmarañada red de relaciones, donde su posición cambiaba de acuerdo con el interlocutor.

Era un oficio complejo, como aprendí de N, otra de las antropólogas del equipo, quien venía de trabajar en una organización indígena a nivel nacional. Cuando hablamos por primera vez, llevaba dos meses sin poder cobrar su sueldo por absurdos administrativos. Además de que por esos días andaba sin plata, los indígenas de la organización de uno de los pueblos bajo su responsabilidad la llamaban cada vez con más urgencia, inquiriéndola por la demora en el giro correspondiente al segundo desembolso del convenio firmado entre ellos y el ministerio.

$\mathrm{N}$ a veces pensaba que sería mejor no contestar al teléfono, porque la respuesta era la misma que había venido dando la última semana: habían tenido que corregir detalles en el informe que le habían entregado y una vez hecho esto, los ritmos propios de las oficinas financiera $\mathrm{y}$ jurídica del ministerio, sobre los que ella no tenía 
control, hacían que no pudiera garantizar que la plata llegara hasta la semana entrante. Ellos no podían esperar tanto, pues tenían atrasados los pagos a sus equipos y ella era consciente de eso. Sin embargo, ahí estaban ambos esperando como el coronel, en una condición compartida, en la que los indígenas le cobraban sin sospechar que ella a su vez también estaba intentando atravesar (por ellos y por ella) el entramado administrativo que los tenía a ambos sin plata.

Al menos a eso se le veía algún tipo de solución, eventualmente las oficinas financiera y jurídica llegarían a la carpeta del convenio con estos indígenas, la tramitarían y la plata del segundo desembolso llegaría por fin a sus destinatarios; era cuestión de pedirles más paciencia y, en lo que a ella respectaba, hacer frente a los retrasos de su pago. Sin embargo, le preocupaba más la situación con el otro pueblo del que estaba encargada, con el que se habían reunido en días pasados para concertar su diagnóstico y sobre el que, además de admirar a su cabildo gobernador, la sobrecogía el hecho de que más de doscientas personas habían sido asesinadas en los últimos quince años. Quizá por la admiración al cabildo, por solidaridad con la situación de riesgo en que estaban o por el hecho de que le hubiesen puesto aseguranzas $^{12}$ cuando empezó a trabajar con ellos, $\mathrm{N}$ estuvo en la concertación aunque ya no era parte de su trabajo, pues había cambiado de cargo al interior del ministerio $\mathrm{y}$, como organizadora de esa reunión, se encontró en la mitad del tire y afloje entre las propuestas de los indígenas y las respuestas, casi siempre evasivas, de las instituciones.
46 la reunión, $\mathrm{N}$ me comentó que es curioso cumu ellos, trabajando en el grupo del Ministerio del Interior, se referían a gente de las instituciones como los de las instituciones, tomando distancia, como si no fueran también parte de ese entramado estatal, con sus respuestas limitadas a declamar que $\mathrm{X}$ solicitud no hace parte de sus competencias o que no hay presupuesto ese año. Había una tensión en ser los intermediarios entre las instituciones y los indígenas, incluso cuando ellos mismos son parte de la institucionalidad. Esa tensión la resumió así E, un antropólogo que llevaba varios años trabajando el enfoque diferencial en diversas instituciones gubernamentales:

Hay funcionarios que vienen entrenados, que les gusta el tema, que les gusta viajar, que les gusta interactuar con las comunidades, como hay otros que no. Y el que llega cerrado a la banda [quien se niegue a cambiar sus opiniones o planes] le va mal, lo levantan y arman problema; todo el que viene abierto, pues como que tendrá tensiones, pero bien. Puede ser amigo de los indígenas a la vez tener que, además que otra cosa, a esos funcionarios les toca pelear adentro. $\mathrm{O}$ sea: pelean por fuera $\mathrm{y}$ por dentro ${ }^{13}$

Me interesa mucho ese "pelean por fuera y por dentro" porque es esa la tensión a la que me refiero. El "dentro" al que se refiere es el interior de la institucionalidad, el "fuera" es el escenario de negociación con los indígenas. Pero también el "dentro" es con los indígenas y el "fuera" es con la institucionalidad, pues su labor implicaba momentos en los que se reconocían y operaban

corporificar la relación que ha sido mediada por mamu, los unku sia son también dispositivos de protección para la persona" (Arenas 2016: 31). Para N, lo más importante de este regalo de las aseguranzas era su propósito de protección.

13 Entrevista a E, contratista de una institución gubernamental del nivel nacional, conducida por Valentina Pellegrino, 3 de octubre de 2013. 
como parte de la institucionalidad frente a los indígenas y momentos en los que se reconocían y operaban como aliados de los indígenas frente a la institucionalidad del Estado.

Esos cambios sobre qué es afuera y qué es adentro me recuerdan la discusión que da Rappaport (2008) sobre la porosidad de las fronteras entre "adentro" y "afuera" de los intelectuales indígenas en la configuración del movimiento indígena en el Cauca, sobre las múltiples posiciones que alguien ocupa y que dependen del contexto. Acá esa porosidad estaba en lo que podían hacer y decir como representantes del ministerio y cómo se conjuga con lo que pensaban, hacían y decían cuando su trabajo no era representar a una institución gubernamental. Esto puede verse mejor cuando $\mathrm{R}$ me decía:

Como que sale de pronto lo que uno pensaba desde la academia antes, o de pronto puede ser un "pajazo mental" de uno, decir: "pues yo desde adentro puedo ayudarles en algo, yo puedo ser un infiltrado de ellos acá, de alguna forma, uno se da cuenta de que a veces es muy difícil, que el sabotaje interno a veces es mucho, si uno lo quiere ver así en términos de teoría de la conspiración, pero, digamos que lo que siento ahí yo es eso, o sea yo soy el Ministerio del Interior, pero yo soy por encima de todo, $\mathrm{R}$, que vengo con una intención personal también de aprender de ustedes, de conocerlos a ustedes y de hacer todo lo posible porque el Estado -en la medida de mis pocas posibilidades que tengo- pueda ser un poco más efectivo. Entonces es como esa la idea que uno se mete y la que a uno le permite venir a trabajar acá todos los días, decir, un día más en el que me levanto a ver si logro algo para esta gente también. $^{14}$
La explicación de $\mathrm{R}$ sobre su lugar en este escenario es fascinante, en la medida en que se reconocía simultáneamente como parte del Ministerio, como infiltrado de los indígenas y como un sujeto que quería aprender de los indígenas con quienes debía relacionarse en su trabajo. Pero además esta triple situación era inestable, es decir, en unos momentos $\mathrm{R}$ es el ministerio y en otros era sencillamente $\mathrm{R}$ :

Pero estamos en una reunión en campo, por ejemplo, con instituciones, y nos tocan las del ministerio y yo no soy $\mathrm{R}$, soy Ministerio del Interior y tengo que dar una mirada siempre edulcorada del asunto, como me ha pasado varias veces. Pues me pasó una vez en territorio fuerte allá en Leguízamo, que nos tocó una reunión de todas las instituciones y llegó una multinacional a mostrar el proyecto IRSA, que es un proyecto de interconexión fluvial, vial, no sé qué para poder sacar, o sea, un tema macroeconómico, a nivel regional, América Latina. El proyecto es tenebroso realmente, si uno lo mira desde la perspectiva ecológica y antropológica: porque es convertir el río Putumayo en un río más grande pa' meter barcos más grandes y acabar con todo. Pero entonces pasan: "bueno, el Ministerio del Interior ¿qué opina sobre esto?" y cuando me toca pasar a mí al frente con el micrófono a decir "no, pues vamos desde el Ministerio del Interior a revisar cómo fue el proceso de consulta previa con ustedes, porque si ustedes no están enterados de esto entonces evidentemente hubo un mal proceso de información, blablablá" pero, pues todo como muy suave [...] Entonces a uno le toca como pilotear eso. Pero yo ese día me acuerdo de que yo solté el micrófono, me fui pa'l mambeadero a donde los abuelos, a pedirles perdón, de una me fui y dije: "abuelo $\mathrm{H}$, vea yo dije esto, pero quiero que entienda que es que

14 Entrevista a R, integrante del grupo del Auto 004, conducida por Valentina Pellegrino, 22 de agosto de 2013. 
yo hablo desde el Ministerio, no puedo hablar desde mi perspectiva, $\mathrm{R}$ hubiera dicho esto y esto y esto ${ }^{15}$

Así, durante una reunión $\mathrm{R}$ actuaba "como ministerio", es decir, como el contratista que habla en nombre del ministerio, pero al finalizar la reunión actuaba como $\mathrm{R}$ en el mambeadero, hablaba desde sí mismo y no desde una institución; además, se asumía desde un lugar de empatía con la situación de los indígenas. Así, R pasó de estar "dentro" del lado de institucionalidad durante la reunión a estar "dentro" del lado de los indígenas al finalizar la misma. $\mathrm{T}$, en cambio, que venía de trabajar en organizaciones indígenas, encontró formas de resolver la tensión del lugar que ocupaba como contratista en Asuntos Indígenas, transitando desde una imagen de infiltración a una de construcción conjunta de nación. Así me explicó, cuando le pregunté qué pensaba sobre estar trabajando en una institución como el ministerio:

Mi maestro fue el profesor [Luis Guillermo] Vasco, entonces ese hombre sí que es... Y la ventaja que yo tuve fue el coordinador, que él me hacía poner los pies en la tierra, o sea "yo soy del otro equipo, yo soy una infiltrada, pues yo estoy es trabajando para la gente", no sé qué, y es que él decía: "es que no hay dos equipos, somos los mismos: tanto ellos como usted, todos somos ciudadanos colombianos, estamos trabajando para la misma conformación de nación, ¡no hay dos equipos!” y fue un trabajo fuerte, fuerte, fuerte para que yo pudiera entender la cosa y pudiera tener la esperanza y la logré viendo el trabajo, viendo con él en campo cómo era la relación con la gente,

\footnotetext{
15 Entrevista a R, integrante del grupo del Auto 004, conducida por Valentina Pellegrino, 22 de agosto de 2013.

${ }^{16}$ Entrevista a T, integrante del grupo del Auto 004, conducida por Valentina Pellegrino, 20 de septiembre de 2013.

${ }^{17}$ Luis Guillermo Vasco es un antropólogo colombiano, quien además fue profesor por más de treinta años del
}

que realmente no era esa relación de poder, que desde el discurso que yo tenía en la cabeza, sino ya en la construcción, en lo real, era distinta. ${ }^{16}$

Me interesa mucho la mención a Vasco ${ }^{17}$ porque él es reconocido por plantear una manera de ejercer la antropología abiertamente militante en favor de la lucha indígena (Vasco 2002). En ese sentido, la intervención de $\mathrm{T}$ nos remite a otro aspecto de la intrincada posición de la gente del grupo del auto y es su formación profesional. Así, como señalé anteriormente, a partir de los convulsionados años sesenta, los antropólogos colombianos plantearon que su profesión era útil, no para adelantar la agenda desarrollista que impulsó su institucionalización en el país, sino para contribuir a la transformación radical de la sociedad, lo cual en muchos casos devino en una antropología militante que acompañó a los movimientos sociales en sus procesos organizativos (Jimeno 2007, Pineda 2005). Este compromiso ha cumplido un rol importante en la construcción de los antropólogos como grupo profesional (L'Estoile, Neiuburg y Sigaud 2005). De ahí que $T$, al igual que $R$, se pensara inicialmente a sí misma como una infiltrada de los indígenas en el ministerio.

Sin embargo, la experiencia de $\mathrm{T}$ le había mostrado que el contexto en el que se construían estas políticas públicas no podía reducirse a indígenas por un lado y funcionarios por el otro, como si se tratara de mundos contrarios; de ahí que dejara de considerarse como infiltrada de los indígenas y empezara a asumir una fluidez en la posición que ocupaba. Esa fluidez implicaba ser muy franca dentro del ministerio sobre el malestar que le generaban los permanentes incumplimientos de los compromisos que firmaron algunas instituciones con el pueblo de 
cuyo plan de salvaguarda se ocupaba, e intentar infructuosamente que la denuncia de estos incumplimientos quedara en el informe de gobierno que se le presentaría a la Corte Constitucional sobre los avances del Auto 004.

Su denuncia no se incluyó porque parte de la idea del informe era precisamente plantear que el gobierno nacional venía cumpliéndole a los indígenas, aunque más lentamente de lo deseable. Así, T intentó aprovechar su posición "dentro" del entramado institucional para hacer una denuncia que podría considerarse como de "afuera", pues era sobre el incumplimiento de las instituciones a los indígenas. Esta posición recuerda un poco al argumento de Jimeno (2007) acerca de la continuación de la antropología militante aún trabajado en las instituciones gubernamentales, pues se intentaba construir una ciudadanía efectiva de las minorías étnicas, cambiando al Estado "desde adentro".

Así, esta oscilación entre adentro/afuera ocurría en las reuniones con los indígenas y con las instituciones, en los documentos que elaboraban $y$ hasta en el espacio que ocupaban en el ministerio; en una encrucijada permanente entre lo que aprendieron de sus maestros sobre su deber como antropólogos, lo que debían hacer en cuanto representantes del Estado y lo que querían hacer en tanto ciudadanos, pues entendían que su trabajo estaba inmerso en las relaciones políticas que se tejen entre el Estado y los pueblos indígenas, las cuales han sido estudiadas y criticadas profusamente desde su disciplina. De ahí que su posición sea compleja, pero a la vez explica que busquen, dentro de su limitado margen de maniobra, transformar al Estado "desde adentro": intentando incluir denuncias en los informes gubernamentales, sensibilizando a los funcionarios de otras entidades públicas sobre la situación de los indígenas o advirtiendo a estos últimos las dos caras de la moneda en los proyectos de infraestructura que les informa alguna institución gubernamental.
A lo largo de este escrito, me referí al recoveco como una metáfora espacial de la posición que ocupaba dentro del ministerio el grupo del Auto $04 \mathrm{y}$, en particular, de los antropólogos que lo conformaban. Así, su condición de contratistas sin experiencia laboral previa en el sector público implicaba una externalidad a la institución, paralela a la de su oficina en relación con la Dirección de Asuntos Indígenas. Al igual que recorrer el recoveco involucraba aprender a moverse entre las cajas con documentos archivados, recorrer la ruta metodológica implicaba, sobre todo, aprender a hacer política pública a través de patinar carpetas: redactar, supervisar o radicar con rapidez los documentos vinculados a los planes de salvaguarda ordenados en el auto. Ahora bien, puede que patinar carpetas no sea algo que se enseñe en los departamentos de antropología, pero indudablemente hace parte de un nuevo momento en el rol que desde antaño ha desempeñado la disciplina al interior del Estado en su relación con los pueblos indígenas.

\section{Referencias}

Arenas, J. (2016). Sembrando vidas. La persona I'ku y su existencia entre lo visible y lo invisible. Tesis de doctorado en antropología. Universidad de Brasilia, Brasil.

Briones, C. (2007). Escenas del multiculturalismo neoliberal, una proyección desde el Sur. En Cultura y neoliberalismo, editado por Alejandro Grimson. Buenos Aires: CLACSO.

Chaves, M. (2011). Presentación a $L a$ multiculturalidad estatalizada: indígenas, afrodescendientes y configuraciones de Estado, editado por Margarita Chaves, 924. Bogotá: ICANH.

Caicedo, A. (2015). La alteridad radical que cura. Neochamanismos yajeceros en Colombia. Bogotá, Colombia: Editorial Uniandes. 
Correa, F (2006). Interpretaciones antropológicas sobre "lo indígena" en Colombia. Universitas Humanística 62: 15-41.

Correa, F. y Acero, S. (2013). Proyecciones del Instituto Indigenista de Colombia en la División de Asuntos Indígenas. Baukara 3:83-98.

García, H. (2010). Una historia de nuestros otros. Bogotá: Editorial Uniandes.

Grey Postero, N. (2007). Now we are citizens: indigenous politics in postmulticultural Bolivia. Stanford: Stanford University Press.

Hale, C. (2002). Does multiculturalism menace? Governance, cultural rights and the politics of identity in Guatemala. Journal of Latin American Studies 34 (3): 485-524.

Hale, C. (2004). Rethinking indigenous politics in the era of the "Indio permitido". North American Congress on Latin America 38 (2): 16-21.

Jaramillo, A. (2016). Las palabras del multiculturalismo estatal en Colombia. Los funcionarios y la garantía de derechos de los emberá y nukak. El caso de la salvaguarda y el enfoque diferencial étnico entre los pueblos indígenas emberá y nukak. Tesis de maestría en estudios latinoamericanos. Universidad Nacional de San Martín, Argentina.

Jimeno, M. (2007). Naciocentrismo: tensiones y configuración de estilos en la antropología sociocultural colombiana. Revista Colombiana de Antropología 43: 9-32.

Jimeno, M. (2008). Colombia: citizens and anthropoligists. En A companion to Latin American anthropology, editado por Deborah Poole, 72-90. Malden: Blackwell Publishing.
Jimeno, M. (2011). El lugar de la diferencia cultural: cambios en la definición de nación. Innovación y Ciencia. 18 (4): 3643.

Langebaek, C. (2009). Los herederos del pasado. Indígenas y pensamiento criollo en Colombia y Venezuela. Bogotá: Editorial Uniandes.

Lemaitre, J. (2009). El derecho como conjuro: fetichismo legal, violencia y movimientos sociales. Bogotá: Universidad de los Andes y Siglo del hombre.

L' Estoile, B, Neiburg y Sigaud. (2005). Introduction: Anthropology and the Government of "Natives", a comparative approach. En Empires, Nations and Natives. Anthropology and State-Making, editado por Benoit L'Estoile, Federico Neiburg y Lygia Sigaud, 1-29. Durham: Duke University Press.

Ministerio de Cultura. (2010). Documentos para la historia del movimiviento indígena colombiano contemporáneo. Bogotá: Ministerio de Cultura.

Pacheco de Oliveira, J. (2005). The anthropologist as expert: Brazilian ethnology between Indianism and Indigenism. En Empires, Nations and Natives. Anthropology and State-Making, editado por Benoit L'Estoile, Federico Neiburg y Lygia Sigaud, 223-247. Durham: Duke University Press.

Padilla, G. (1996). La ley y los pueblos indígenas en Colombia. Journal of Latin American Anthropology 1 (2): 78-97.

Pellegrino, V. (2007). Incumplir cumpliendo: una etnografía al papeleo del Auto 004. Tesis de doctorado en antropología. Universidad de los Andes. 
Pels, P. (1999). Profession of duplexity: a prehistory of ethical codes. Current Anthropology 40(2): 101-136.

Pérez, M. (2007). Las perspectivas y retos de la antropología aplicada en el siglo XXI. Revista Mad 16: 1-9.

Pineda, R. (1997). La Constitución de 1991 y la perspectiva del multiculturalismo en Colombia. Alteridades 7(14): 107-129.

Pineda, R. (2005). La enseñanza de la antropología en Colombia. Universitas Humanística (59) 11-21.

Ramos, AR. (2011). Indigenismo: um orientalismo latinoamericano. Anuário antropológico 2011-I, 2012: 27-48.

Rappaport, J. (2008). Utopías interculturales públicos, experimentos con la cultura y pluralismo étnico en Colombia. Bogotá,
Colombia: Universidad del Rosario y Universidad del Cauca.

Rose, N. (1997). El gobierno en las democracias liberales "avanzadas": del liberalismo al neoliberalismo. Archipiélago 29: 25-40.

Sarrazin, JP. (2012). New Age en Colombia y la búsqueda de la espiritualidad indígena. Revista colombiana de antropología 48 (2):139-162.

Sarrazin, JP. (2015). Representaciones sobre lo indígena y su vínculo con tendencias culturales globalizadas. Anagramas 14 (27): $163-184$

Uribe, C. (2002). El yajé como sistema emergente: discusiones y controversias. Documentos CESO 1 (33), pp. 1-65.

Vasco, LG. (2002). Entre selva y páramo. Viviendo y pensando la lucha india. Bogotá, Colombia: ICANH. 